East African Medical Journal Vol. 77 No. 3 March 2000

SOCIO-ECONOMIC SUPPORT FOR GOOD HEALTH IN RURAL MALAWI

T. Kulmala, MD, Medical School, University of Tampere, Finland, School of Public Health, University of Tampere, Finland, M. Vaahtera, MD, Medical School, University of Tampere, Finland, M. Ndekha, MSc, T. Cullinan, MD, College of Medicine, University of Malawi, Blantyre, Malawi, M-L. Salin, DrPH, College of Medicine, University of Malawi, Blantyre, Malawi, Mannheim League for Child Welfare, Mangochi, Malawi, A-M. Koivisto, BSc, School of Public Health, University of Tampere, Finland and P. Ashorn, MD, Medical School. University of Tampere, Finland.

Request for reprints to: Dr. T. Kulmala, University of Tampere Medical School, P.O. Box 607, FIN-33101 Tampere, Finland

\title{
SOCIO-ECONOMIC SUPPORT FOR GOOD HEALTH IN RURAL MALAWI
}

\author{
T. KULMALA, M. VAAHTERA, M. NDEKHA, T. CULLINAN, M-L. SALIN, \\ A-M. KOIVISTO and P. ASHORN
}

\begin{abstract}
Objective: To study the socio-economic support for good health among subsistence farmers in rural Malawi.

Design: A cross-sectional survey.

Setting: Lungwena, a rural area with 17000 inhabitants in southern Malawi.

Participants: Seven hundred and ninety five pregnant women who attended the antenatal

clinic at Lungwena Health Centre between June 1995 and September 1996.

Interventions: Interviews about socio-economic conditions. Measurements of cultivated land areas and distances between home and the local health centre.

Main outcome measures: Proportion of households lacking literate adults, adequate water source and sanitation, easy access to modern health care or food security.

Results: Only 14\% of the interviewed women could read and write and half of the households had no literate members. Every fifth household was lacking both an access to safe drinking water and a proper sanitary facility. The distance to the health centre was more than $5 \mathbf{~ k m}$ among half of the households and only $37 \%$ had enough land to grow food for all family members. When other potential means of obtaining food were taken into account, $27 \%$ of the households had no food security. Numerous households were lacking more than one socioeconomic prerequisites of good health: three or more were missing from a quarter of the families.

Conclusions: Socio-economic prerequisites of health were commonly missing in Lungwena. Subsequent health interventions should strengthen the investments into general poverty alleviation.
\end{abstract}

\section{INTRODUCTION}

The uneven distribution of health and health services in the world has been a matter of public concern for a long time. In the early 1970's, the Director General of WHO gave several reports on the world health situation indicating that, especially in low-income countries, much of the rural population lacked proper access to health services. According to these reports, better equity was the target and primary health care at the community level was seen as the best strategy towards it(1). In 1978, an international primary health care conference was held in Alma-Ata, Kazakhstan. This meeting resulted in the declaration of Alma-Ata, the first serious attempt towards a global health policy, outlining the steps towards attainment of an acceptable level of health for all people in the world by the year 2000(1,2).

The Alma-Ata declaration was one of the first official documents clearly stating that health was not an isolated entity but dependent on various economic and social factors in the environment. It also described the social structures necessary for achieving better health and gave primary care a clear priority in the fulfillment of people's health needs. Importantly, besides the more traditional curative and preventive services, the declaration included health promotion as an integral part of primary health care. Thus, food security, clean water and appropriate housing, education and access to preventive and curative health services were considered to form the prerequisites of good health, both in industrialised as well as in low-income countries $(1,2)$.

Since the Alma-Ata meeting, primary health care has formed a cornerstone of most national health strategies all over the world. Despite the good will translation of primary health-care into health for all has been slow, especially in many low-income countries(3). To analyse whether the slow rate of progress was associated with inadequate socio-economic support for good health, we studied the housing conditions, access to modern health-care, level of education and food security among a group of pregnant women in rural Malawi.

\section{MATERIALS AND METHODS}

Study area: Malawi is a poor south-east African country with approximately 10 million inhabitants. National data indicate serious health problems both among adults and children. Currently, the maternal mortality rate is estimated at 620 deaths 
/ 100000 deliveries. Life expectancy at birth is only 44 years, largely because of high mortality amongst the children. Infant mortality rate is 135 and under-five mortality rate 215 deaths / 1000 live born babies(4).

The present study was done in Lungwena, a rural area near the southern tip of Lake Malawi. The distance between Lungwena and the nearest town, Mangochi, is 30-40 km. Most of the 17000 inhabitants belong to the ethnic group of Yaos. Kinship and inheritance are matrilineal and marriages matrilocal. A governmental health centre providing free primary care is located in the middle of the area. Besides this centre, people can obtain modern health care either from two charging mission facilities located some $20 \mathrm{~km}$ from Lungwena health centre or from the district hospital in Mangochi. Additionally, numerous traditional healers are known to practice in the area, but there are no data on the relative popularity of modern and traditional alternatives for health care.

Enrollment and participants: All pregnant women presenting for antenatal care at Lungwena health centre between June 1995 and August 1996 were briefed about the study and offered a possibility to participate. Before enrollment, informed consent was obtained verbally from each participant. The study plan was reviewed and approved by the Malawi National Health Science Research Committee.

Collection and interpretation of socio-economic data: Most of the information was obtained through personal interviews at the participants first antenatal visits. The interviews were carried out by five local research assistants using structured and pretested native-language questionnaires. Data entry was done with EPIINFO 6.04b programme and the analysis with Microsoft Excel 6.0 spreadsheet programme and SPSS 7.5 statistical software package.

Since Lungwena Health Care Centre is the only governmental health facility providing free curative and preventive health services in the area, distance between people's homes and the Lungwena Health Centre was used as a measure of participants' physical access to modern health care. The distances were measured by driving a motorcycle with an odometer along the roads and paths the women usually used. Educational levels were described by the numbers of completed school-years and the self reported ability to read and write.

Food security was assessed with two different approaches taking into consideration alternative methods of obtaining energy and nutrients. In the first approach, only those households with adequate land area ( 0.2 hectares / person) to potentially grow enough maize for all members in the family, were considered to have food-security. In the second alternative, also those households, who possessed less land but theoretically had a potential for regular cash income considered to have had food security. In the latter group, we included all households that either had: (a) at least two adult members economically supporting the family, (b) a fisherman in the family and; (c) possessed either six chickens, two goats, or one cow per person. These criteria were selected because the sale of fish or domestic products forms the main source of cash income in Lungwena. The numbers of domestic animals were based on consultations of local inhabitants and a market survey that revealed that a week's ration of maize could be bought with eggs laid by six chicken.

Sizes of cultivated land areas were measured by professional extension workers employed by the Ministry of Agriculture (Lungwena Extension Planning Area). In order to test the internal validity of the data, $10 \%$ of the measurements were repeated by another extension worker from the same office. There were no significant differences between the two measurements ( $\mathrm{p}=0.19$, Wilcoxon signed-rank test).
Accumulation of socio-economic risk factors was analysed by counting the number of missing determinants of health for each household. The risk factors included inadequate water supply and sanitation (either an unsafe water source or missing sanitary facility), insufficient educational level of the parents (neither parent could read), food-insecurity (assessed by the extended criteria), and inadequate access to modern health care (distance more than $5 \mathrm{~km}$ ).

\section{RESULTS}

Of the 799 women attending the Lungwena Health Centre antenatal clinic during the study period, 797 (99.7\%) chose to participate. Two of the women were not pregnant. Thus, a total of 795 subjects were enrolled. As indicated by the background characteristics shown in Table 1, the participants were predominantly poor Muslims, who made their living from subsistence farming, supplemented by fishing and small-scale trading. Active surveillance during and after enrollment identified 37 pregnant women who were not receiving antenatal services from Lungwena. Thus, 95.2\% (795/834) of all pregnant women in the area participated in the study. There were no demographic differences between those women who attended Lungwena health centre and those who did not.

Table 1 summarises the water source, sanitation and main housing characteristics for the participants. Approximately one third of the women lived in households that collected drinking water from a source that could be considered "safe" (borehole or protected well). Three quarters reported having a sanitary facility at home. Sixtysix per cent were lacking either a safe water source or a sanitary facility and one fifth (19\%) of the households possessed neither of these facilities.

\section{Table 1}

Background characteristics of 795 study participants

\begin{tabular}{|c|c|}
\hline \multicolumn{2}{|l|}{ Age: } \\
\hline -mean $( \pm \mathrm{SD})$ age of participants & 26 ( 8.7 years) \\
\hline -proportion of under 20 year olds & $21.8 \%$ \\
\hline \multicolumn{2}{|l|}{ Parity: } \\
\hline -mean $( \pm \mathrm{SD})$ number of earlier pregnancies & $2.5(2.4)$ \\
\hline -proportion of primigravid women & $23.8 \%$ \\
\hline \multicolumn{2}{|l|}{ Marital status: } \\
\hline -married & $96 \%$ \\
\hline -single, divorced or widowed & $4 \%$ \\
\hline \multicolumn{2}{|l|}{ Religion: } \\
\hline -Muslims & $95 \%$ \\
\hline -Christians & $5 \%$ \\
\hline \multicolumn{2}{|l|}{ Occupation: } \\
\hline -housewives & $92 \%$ \\
\hline -farmers & $5 \%$ \\
\hline -others & $3 \%$ \\
\hline \multicolumn{2}{|l|}{ Occupation of husbands: } \\
\hline -fishermen & $40 \%$ \\
\hline -farmers & $19 \%$ \\
\hline -small-scale traders & $19 \%$ \\
\hline -others & $22 \%$ \\
\hline \multicolumn{2}{|c|}{ Ownership of domestic animals or household durable goods: } \\
\hline -cows & $3 \%$ \\
\hline -goats or sheep & $25 \%$ \\
\hline -chicken & $34 \%$ \\
\hline -mattress & $11 \%$ \\
\hline -radio & $36 \%$ \\
\hline -bicycle & $27 \%$ \\
\hline -car & $1 \%$ \\
\hline
\end{tabular}

$\mathrm{SD}=$ Standard deviation 
Table 2

Housing conditions for the 795 participants

\begin{tabular}{lc}
\hline Number of household members: & \\
-mean $( \pm$ SD) number of household members & $3(1.5)$ \\
-number of under five-year old children & \\
$\quad$ none & $52 \%$ \\
$\quad$ one & $41 \%$ \\
$\quad$ two or more & $7 \%$ \\
House construction: & \\
-burnt brick & $19 \%$ \\
-unburned brick & $70 \%$ \\
-mud, straw or other & $11 \%$ \\
Size of house & \\
-two or more rooms & $16 \%$ \\
-one room & $84 \%$ \\
Source of drinking water: & \\
-piped water or borehole & $12 \%$ \\
-protected well & $21 \%$ \\
-unprotected well & $39 \%$ \\
-lake, river or pond & $28 \%$ \\
Sanitation facility: & \\
-traditional pit latrine & $77 \%$ \\
-none & $23 \%$ \\
Kitchen: & $58 \%$ \\
-separate outside kitchen & $39 \%$ \\
-outside fireplace & $1 \%$ \\
-inside house & $2 \%$ \\
-others or not known & \\
\hline
\end{tabular}

$\mathrm{SD}=$ Standard deviation

Table 3 presents the frequency distribution of distances between participants' home and Lungwena health centre. The mean $( \pm$ SD) distance was $5.2( \pm 2.9) \mathrm{km}$. Half of the study participants lived further than $5 \mathrm{~km}$ away from the health centre.

Table 3

Frequency distribution of distances between home and health centre

\begin{tabular}{lc}
\hline Distance to health centre & Proportion of households ${ }^{1}$ \\
\hline$<2.5 \mathrm{~km}$ & $26.3 \%$ \\
$2.5-4.9 \mathrm{~km}$ & $21.5 \%$ \\
$5.0-7.4 \mathrm{~km}$ & $23.3 \%$ \\
$7.5-9.9 \mathrm{~km}$ & $19.1 \%$ \\
$10 \mathrm{~km}$ or more & $9.8 \%$ \\
\hline
\end{tabular}

$1_{\mathrm{n}=795}$

Table 4

Educational level of study participants and their husbands

\begin{tabular}{llllr}
\hline $\begin{array}{l}\text { School level } \\
\text { (years completed) }\end{array}$ & $\begin{array}{l}\text { None } \\
(0)\end{array}$ & $\begin{array}{l}\text { Primary } \\
(1-4)\end{array}$ & $\begin{array}{l}\text { Primary } \\
(5-8)\end{array}$ & $\begin{array}{r}\text { Secondary } \\
(9+)\end{array}$ \\
\hline Women & $83 \%^{1}$ & $8 \%$ & $8 \%$ & $1 \%$ \\
Men & $63 \%$ & $13 \%$ & $20 \%$ & $4 \%$ \\
Both sexes combined & $74 \%$ & $11 \%$ & $13 \%$ & $2 \%$ \\
\hline
\end{tabular}

${ }^{1}$ proportion from total population ( $\mathrm{n}=774$ for women, 616 for men)

The frequency distribution of the highest educational levels reached by the study participants is shown in Table 4. Only every sixth woman and every third man had gone to school at all and few had attended secondary school (more than 8 years of education). Accordingly, only $14 \%$ of the women and $43 \%$ of their husbands were reported to be able to read and write. Half $(52 \%)$ of the families had no literate adults.

Most women had a piece of land, where they could grow maize or other plants, but the area was usually rather small (Figure 1). The mean holding size was 0.6 hectares (ha) and three out of five households had a plot that was smaller than half a hectare. Taking into account the number of people sharing the crop, $29 \%$ of the households possessed less than 0.1 hectare of land / person in the household and $63 \%$ less than 0.2 hectare. The latter cut-off point ( 0.2 ha / person) is considered a minimum to provide food security from one's own agriculture in Lungwena.

Figure 1

Frequency distribution of cultivated land areas among 782 smallholders in Lungwena

Twelve per cent of the households were reported to be economically supported by more than one adult and $40 \%$ had a fisherman in the family. A little less than two per cent had at least 6 chickens/person, $11 \%$ at least 2 goats/person and $5 \% 1 \mathrm{cow} /$ person. Seventy-three per cent of the households either had an adequate land area (At least 0.2 ha/person) or possessed one or more of the above mentioned potential sources of cash income (two or more supporters, a fisherman in family or enough animals to sell their products). More than a quarter of the households had no means of securing enough food for all family members.

Several households lacked more than one socioeconomic determinants of health (adequate water supply or sanitation, adequate access to modern health care, literate adults, and food security). The mean (SD) number of missing socio-economic determinants of health was two(1) per household. The proportion of households lacking none, one, two, three or four elements of good health was $8 \%, 24 \%, 40 \%, 23 \%$ and $5 \%$, respectively.

\section{DISCUSSION}

The aim of the present study was to analyse the frequency of appropriate socio-economic support for good health 
among subsistence farmers in rural Malawi. For this purpose, we studied the prevalence of adequate housing, educational level, access to modern health care and food security within the households of 795 pregnant women. In the virtual absence of contraceptive use and almost $100 \%$ antenatal clinic (ANC) enrollment, recruitment of all consecutive ANC attenders ensured an unbiased inclusion of households from all potential socio-economic strata in the community. Men or older women living alone were naturally missed with this approach, but the number of such people is small in this community. As nearly all eligible women chose to participate, we conclude that the sample was well representative of all households in the area.

The socio-economic support for good health was far from being adequate in Lungwena. Thus, the majority of the households had no access to safe water and sanitation, and adult literacy rate was very low, especially among the women. Both of these features have been associated with malnutrition, increased childhood mortality and other health problems, although the mechanisms of action are not completely clear(5-8). Access to health care was also suboptimal, as half of the people lived further than $5 \mathrm{~km}$ away from the hospital. Since walking is the means of transportation for most people in Lungwena, travelling five $\mathrm{km}$ takes approximately one hour, thus efficiently restricting access to modern care. Indeed, we have observed an indirect relationship between the distance from home to the health centre and the use of curative services. Others have also shown that such a long distance to a health facility is one of the most important determinants in the decision not to seek modern health care even when needed(9).

The cultivated land areas were strikingly small in Lungwena, considering that most of the households made their living from subsistence farming. Theoretically, if unfertilized maize is cultured, the minimum plot size for a farmer household in Lungwena would be 0.2 hectares/ person. This estimate is based on the assumptions of a maize yield of $800 \mathrm{~kg} / \mathrm{ha}$ and a million loss of $18 \%(10)$. In these conditions, a hectare would produce approximately 2.2 million kilocalories (kcal) of energy, enough to support the living of 1000 adults for one day (2 $200 \mathrm{kcals} / \mathrm{day})$. Since one third of the household members were children (who needed on average $50 \%$ of an adult's intake) and since maize contributed to two thirds of the total energy intake for people in Lungwena the size of maize fields for farmer households should be at least $0.2 \mathrm{ha} /$ person. Our survey indicated, that only one third of the families controlled this amount of land. Thus, it appeared evident that farming alone could not fulfill the dietary needs of the population in Lungwena.

A large proportion of households had potential sources of extra income, either through the sale of fish or domestic animal products or through an additional adult economically supporting the family. Thus, the inadequate land areas could partially be balanced by cash money that could be used for purchasing food. However, even when all these potential sources of income were considered, more than a quarter of the people appeared to live in households with inadequate food security. Moreover, this figure might be a significant underestimate, since the money obtained through the sale of fish or domestic products was not necessarily directed towards the procurement of food for all members in the family. It is therefore, evident that the small plot sizes seriously limited food security in Lungwena, which, in turn, is likely to be a hindrance to positive development in this area.

Our results have shown that a large number of people in rural Malawi are still lacking the socio-economic support for good health, 20 years after the Alma-Ata Conference. In the light of these results and those of previous studies, subsequent health interventions should strengthen the investments into general poverty alleviation(11-13). The access to good quality medical services should be developed concomitantly, since in their absence even significant socio-economic changes may fail to improve health in the general population(14). Thus, both of these aspects need to be taken into consideration when planning health interventions in Malawi and in other low-income countries.

\section{ACKNOWLEDGEMENTS}

We are grateful to the people of Lungwena, the staff at the Lungwena Training Health Centre and our research assistants for their positive attitude, support and help in all stages of the study. Professors J. Chiphangwi, N. Hallman and J. Visakorpi are acknowledged for their valuable comments and continuous support. The study was financially supported by grants from the Academy of Finland, Emil Aaltonen Foundation for Paediatric Research in Finland, Medical Research Fund of Tampere University Hospital, the Research Foundation of Mannerheim League for Child Welfare and the Research Foundation of the University of Tampere.

\section{REFERENCES}

1. Hellberg, H. and Mäkelä, M. Health for all or someone only? In: Health and Disease in Developing Countries: Lankinen, K.S., Bergström, S., Mäkelä, P.H. and Peltomaa, M. (eds). Hong Kong, Macmillan Press, 1994.

2. WHO: Health for all series, No. 1: Alma-Ata 1978: Primary Health care. Geneva. WHO, 1978.

3. Bergström, S. and Mocumbi, P. Health for all by the year 2000? No, and not for many generations without concrete and credible actions to alleviate poverty. Brit. Med. J. 1996; 313:316.

4. UNICEF: The state of the world's children 1999. UNICEF.

5. Lindskog, U. Child health and household water supply: An intervention study from Malawi. Linköping, 1987.

6. Reed, B.A., Habicht, J.P. and Niamego, C. The effects of maternal education on child nutritional status depend on socio-environmental conditions. Int. J. Epidem. 1996; 25:585-592.

7. Cleland, J.G. and Ginneken, J.K. Maternal education and child survival in developing countries: the search for pathways of influence. Soc. Sci. Med. 1988; 27:1357-1368.

8. Harrison, K.A. The importance of the educated healthy women in Africa. Lancet. 1997; 349:644-647.

9. Thaddeus, S. and Maine, D. Too far to walk: Maternal mortality in context. Soc. Sci. Med. 1994; 38:1091-1110.

10. UNICEF and Government of Malawi. Situation analysis of poverty in Malawi. Limbe: Montfort Press, 1993.

11. Quinn, V., Chiligo, M. and Gittinger, P.J. Malnutrition, household income and food security in rural Malawi. Hlth. Polic. Plann. 1990; 5:139-148.

12. Pastore, G., Branca, F., Demmissie, T. and Ferro-Luzzi, A. Seasonal energy stress in an Ethiopian rural community: an analysis of the impact at the household level. Eur. J. Clin. Nutr. 1993; 47:851-862.

13. UNICEF. The state of the World's children 1998. New York. Oxford University Press.

14. Caldwell, C.C. Old and new factors in health transitions. Hlth. Trans. Rev. 1992; 2:205-216. 